\title{
LESSONS FROM A NATIONAL MENTAL HEALTH ARTS FESTIVAL
}

\author{
Gail Aldam a, Rob Dickie a, Lee Knifton a, b, and Larry Davidson c
}

a Mental Health Foundation, Scotland, United Kingdom; b University of Strathclyde, Scotland, United Kingdom; c Department of Psychiatry, School of Medicine, Yale University, New Haven, Connecticut, USA

\begin{abstract}
The Scottish Mental Health Arts and Film Festival has evolved over the last 10 years into one of the world's largest mental health events, engaging more than 30,000 people each year. The model of the festival will be outlined and the evolution traced over three distinct phases: from its inception as an anti-stigma campaign, to a broad-based social movement harnessing grassroots activism, and finally, to achieving international reach and artistic recognition. The first phase details the inception and early incarnations of the festival, building upon Allport's contact theory model that the most effective way to reduce stigma is through positive personal contact with someone in a valued social role. The learning demonstrated that the festival could achieve large-scale reach among the most marginalized communities and increase positive perceptions and intentions among audience members. As the festival evolved into its second phase, artists and activists began to develop events and grassroots partnerships throughout Scotland. A feature of the festival at this stage, as people with and without mental health diagnoses worked together, was that many events explored "mental health identities" in a broader sense, and this led many of those involved to reframe their ideas of mental health and illness. The third phase explores the impact of the festival at a broader social level.
\end{abstract}

\section{Introduction}

The last two decades have seen an increasing global understanding of the detrimental roles stigma and discrimination play as barriers to accessing mental health services and as impediments to recovery and the community inclusion of persons with mental illnesses (Corrigan \& Watson, 2002). In 2001, the Scottish Government had developed a national program for improving mental health, titled Towards a Mentally Flourishing Scotland, which aimed to challenge stigma associated with mental illness and promote positive mental health for the population (Scottish Government, 2009). However, in 2008, a review was published highlighting only limited improvements in public attitudes, particularly among low income and minority ethnic communities (Health Scotland, 2008). As one response to these findings, we envisaged that the arts could play a role in embedding these existing public mental health campaigns more effectively at the individual and community level. The concept for the Scottish Mental Health Arts and Film Festival arose through this need to identify new ways to campaign against mental health stigma and discrimination.

The Festival founders had developed community work based upon Allport's (1954) contact hypothesis, which argues that the most effective way to reduce stigma is through positive contact between the subjects and perpetrators of prejudice. Building on Allport's theory, we considered that a Festival might provide a platform for this contact in a safe and meaningful way, at a scale that could make a significant difference. We hoped that as audiences attended arts events exploring mental health in various ways, they would have the opportunity to positively engage with people with lived experience of mental ill health who were occupying valued social roles. This could be either indirectly, through watching a performance or film, or directly, by engaging in discussions with artists and experts. This process was intended to have the effect of instigating positive change in 
audience perspectives about, and behavior toward, people who experience mental health conditions.

This article explores key elements of the Scottish Mental Health Arts and Film Festival, which has evolved over the last 10 years into one of the world's largest mental health events, engaging more than 30,000 people each year. The model of the festival will be outlined and the evolution traced over three distinct phases: from its inception as an anti-stigma campaign, to a broad-based social movement harnessing grassroots activism, and finally, to achieving international reach and artistic recognition.

\section{Phase one: Getting started}

The first Festival took place in October 2007, led by the Mental Health Foundation and supported by See Me, Scotland's program to end mental health stigma and discrimination, and the National Health Service. We began in two regions, Glasgow and Lanarkshire, which encompass some of the highest areas of poverty and health inequalities in western Europe. The Festival was scheduled to coincide with World Mental Health Day (WMHD), enabling organizers to take advantage of increased interest in mental health around that date. Although WMHD is a significant global event, aimed at raising awareness of mental health issues, it focuses on mental health education and advocacy like the vast majority of mental health campaigns (World Federation for Mental Health, 2010). Although we felt that this was a very important approach we believed that it could risk oversimplifying mental health issues that more often than not are complex and contested concepts. We believed in the need for a more nuanced exploration of such issues that would be possible through the arts. In this way, the Festival could become a focus for campaigning around this date in Scotland, offering people the opportunity to explore mental health in a more engaging and emotive way.

The Festival was initially conceived as a weekend of film to be held in Glasgow but grew in that first year into a 2-week long event developed alongside multiple partners, supported by a network of more than 40 organizations from the arts, public, community, and voluntary sectors. The program featured around 40 events encompassing film, theatre, comedy, concerts, community events, debates, discussions, and workshops. As a whole, the Festival explored the multifaceted relationship between mental health and creativity, and all events in the program took as their theme the relationship between mental health and artistic inspiration. It was important from the outset that every effort was made to keep events accessible. Available data at that time showed that arts attendance was considerably lower among citizens from ethnic minorities, areas of socioeconomic deprivation, or who were older (Scottish Arts Council, 2008). Therefore, all events were either free or very low cost, reducing one of the main barriers to engagement with the arts, and many were jointly developed and promoted in partnership with community organizations.

Even in this first phase of the Festival's development, efforts were made to explore other aims that would be expanded on in the years that followed. It was always an ambition to create connections across diverse segments of society, and this led to events that brought together people with lived experience of mental health issues, artists, academics, activists, and experts, through moving conversations and insights into mental health. The Festival also sought to develop audiences for the arts and mental health in Scotland, encouraging artists with lived experience to participate and lead events. Our explicit aim in this was to promote understanding and recovery, as well as to reduce self-stigma, and develop and market events that would appeal to people interested in mental health issues but who do not normally participate in the arts. To ensure credibility within the art world, it was also important that the Festival focused on its artistic output, embedding the creation of new work. 
The first Festival surpassed initial expectations, not only in terms of the number and diversity of events that were programed, but also the impact that it had (Quinn, Shulman, Knifton, \& Byrne, 2011). Our primary goals at this stage were to influence the public and the media as the sources of stigma. We aimed to reduce public prejudice by attracting large and diverse audiences and having a positive impact upon their beliefs, attitudes, and behaviors. Additionally, we hoped to positively influence media reporting to gain wider social impact. An early body of research on audience impact was very encouraging. A study of audience impact was undertaken combining quantitative and qualitative approaches to explore changes to knowledge, attitudes, and behavioral intent, with more than 400 attenders at 20 events (Quinn et al., 2011). This study showed that the audiences had a broad range of views before attending and that events consistently increased positive attitudes, including positive representations of people's contributions, capabilities, and potential to recover. However, what also emerged was that an arts event could reinforce pre-existing prejudice and beliefs about dangerousness if it did not include meaningful contributions from people with lived experience of mental ill health. This reinforces Allport's (1954) hypothesis about the role of personal contact in prejudice reduction, in that contact itself is not sufficient but that it should be in the context of equal status, personal interaction, and meaningful, collaborative activity.

The second ambition, to positively influence media reporting, stemmed directly from an earlier study of media reporting of mental health in the years preceding the festival by Knifton and Quinn (2008). This study analyzed trends in media coverage of mental health in the early years of the national program for mental health and found that traditional media lobbying approaches had been broadly successful in reducing negative reporting of people with mental health conditions as dangerous. However, this had been achieved at the cost of reducing overall coverage of mental health, including a reduction in positive representations of people with mental health conditions as partners, parents, employees, and so on. This was a source of real concern, and it was hoped that the Festival might create a rich source of news-worthy, engaging, and positive stories for journalists and media to cover to help to counter this trend. Coverage in print and social media was extremely high in the early years. Events that involved Scottish artists and celebrities, especially musicians who had experienced mental health conditions, captured the media's attention at a time when positive stories about mental health were rare. However, though coverage was positive, it also included discussion about some of the challenges that the Festival would face in the future, questioning how sustainable an arts event that focused solely on a stigmatized issue like mental health really was. Was it possible to explore mental health in a complex and realistic way, moving away from popular and easily romanticized notions about the relationship between mental health and creativity, without alienating audiences? For example, Phil Miller, arts correspondent at the national newspaper The Herald, wrote:

It will be interesting to see whether the Festival leads to its ambitious aims: a wider discussion of mental health issues in society. But it would be good to see, perhaps in its second incarnation next year, a direct approach taken to analysing the mysteries and complexities of the human mind that produce art in all its facets. But it will not be easy. The truth might be, in more than one way, too painful. (Miller, 2007)

Despite these underlying concerns, the first Festival received highly positive response from artists, audiences, and potential partners. It was clear that people really welcomed a new approach to mental health campaigning, particularly those with lived experience themselves and also artists, and organizers who believed that there was tremendous potential for development but mindful of the ethical issues involved (Knifton, Quinn, Inglis, \& Byrne, 2009). Over the next few years, regions throughout Scotland would become involved and a grassroots social movement would emerge. 
Having been originally intended as a weekend of film and discussion, focusing on reducing mental health stigma and discrimination, the Festival had begun to evolve into a substantive and fully national arts event, exploring mental health in its broadest sense.

\section{Phase two: Developing a social movement}

During its second phase of development, the Festival expanded its reach and engagement with communities throughout Scotland. Our hope was to develop a social movement through art. From 2008, the Festival's second year, extensive work was carried out to harness and mobilize the energy of mental health groups throughout the country, providing an outlet to explore new creative approaches to campaigning.

\section{Coproduction and the "hub-and-spoke" model}

Regional networks were developed, allowing hundreds of new partners and grassroots organizations to become involved, a process that enabled the Festival to scale up in a way that was sustainable and organic. Resource constraints played a part in the thinking behind this approach, given that the Festival had a modest budget and relied on a small team of part-time staff, but this model also helped to establish the ethos of a social movement. In its second year, the Festival programed events across five regions in Scotland. By the end of its second phase, it was active in 17 regions covering virtually the entire country, from the major cities to the Highlands and Islands, with annual attendance of more than 15,000.

These developments resulted in a unique "hub-and-spoke" planning and programming model, which remains a key feature of the Festival today. Based in Glasgow, Scotland's largest city, the core team manages the Festival as a whole, programming a series of headline events in multiple art forms and providing support to satellite regional planning groups across the country. These groups are given responsibility for programming in their regions, with the freedom to fundraise and program events, enabling them to respond to the needs of their communities and target local audiences in a way that would not be possible if managed centrally. Events are then combined by the core team and promoted as a single national program, ensuring that every event, regardless of its scale or budget, benefits to some extent from media and marketing campaigns carried out by the Festival's core team. The success of this hub-and-spoke model has depended on building broad alliances with individuals and organizations throughout Scotland. Regional planning groups involve people from various disciplines and backgrounds, including artists, activists, public and voluntary sector organizations, National Health Service bodies, academics, and people with lived experience of mental ill health.

The hub-and-spoke model is centered on cocuration and coproduction with communities across Scotland, ensuring that lived experience informs all aspects of the programming, which is essential to the Festival's aim of producing arts events that represent the broad range of mental health identities that exist in Scotland. By providing a platform for people with lived experience to be heard, the Festival helps to instill a strong sense of ownership over the program and empowers organizers to create events that will resonate with the communities they are hoping to reach. This cocuration and coproduction model was essential to the Festival's development in its second phase. Studies have indicated that the Festival reaches people with lived experience of mental ill health, people from low- income households and Black and minority ethnic communities particularly effectively, with all three groups represented in higher proportions in Festival audiences than are present in the Scottish population (Inglis, Knifton, Quinn, Dougal, \& Byrne, 2011). The Festival has also been shown to engage people that do not typically participate in the arts in high numbers 
(Scottish Arts Council, 2008), as well as people that national mental health campaigns often struggle to reach (Myers et al., 2009). Furthermore, research suggests that the Festival's success in reaching these marginalized groups can be attributed to the model that has been established. By playing a direct role in programming and developing events, communities have been able to shape their local Festival program to address their own concerns and build on the work that local services are already carrying out. This has ensured that even niche events have the capability to attract audiences in meaningful ways and in sufficient numbers.

As is the case with many social movements, there have been some challenges with the hub-andspoke model. The individuals and organizations involved can have different motivations for taking part, and contrasting ideas about what the Festival represents and its artistic output. Although it is important that this is managed carefully, it can also provide an important source of creative tension, ensuring that the team remains constantly mindful of the complexity of mental health, and the issues with which it is inextricably entangled. The Festival has always provided an opportunity to celebrate individuality, while contributing to the wider ambitions of a national collective. To establish this, the Festival's structure is designed to be nonhierarchical as far as this is practically achievable, ensuring that everyone is involved in decision making, through open meetings and regular communication, on a regional and national level. Managing the Festival in this way therefore represents a process of "cultural organizing" (Kuttner, 2015).

\section{Artistic impact and impact on artists}

During its second phase, the Festival also placed further focus on programming high profile events, in partnership with established and emerging artists and arts organizations. These events were balanced with community-led events in the program and often selected to complement grassroots activities. There was a particular emphasis on supporting events that would tour to multiple areas, providing an important thread to connect work taking place across different regions, and ensuring that audiences in regions with limited arts provision benefited from higher standards of arts programming.

Instead of commissioning new work during this phase, the Festival focused on curating and supporting existing work, which matched its ethos, while facilitating complementary discussion events. Artists were encouraged to develop new work exploring mental health issues, and the Festival often provided assistance with funding applications to support projects. However, at this time, the core team did not seek arts funding for the Festival overall, not wishing to take funding away from other arts organizations while its primary objectives remained in social justice. Decisions to support rather than commission work were also rooted in the Festival's need to remain financially sustainable, particularly during a period of public funding cuts. We operated on a relatively small budget that was largely made up of funding from public bodies, particularly in the health sector.

One unexpected result of the Festival during this phase of artistic development has been the impact it had on many of the artists that were involved, on a personal and professional level. By coproducing events as well as performing to, and engaging in discussions with, new audiences, artists were able to gain a better understanding of the inherent complexity in representing mental health in creative work, as well as the emotional responses that can be generated when this is done effectively. Choreographer Emma Jayne Park, who has toured four productions in more than eight years and is now the Festival's associate artist, described in an interview the impact this work has had on her own career: 
My [festival] work spans from working in mental health centres and touring work to audiences [both] familiar with dance and not familiar with dance .... It's introduced me to some very forward thinking people who really promote mental health as mental health, not just mental [illness], which is huge. It's really easy to get caught up in media stereotypes ... whereas being part of the Festival has shown me time and time again how complicated the conversations are, and that it's OK to be part of a complicated conversation. (E. J. Park, personal communication, November 4, 2016)

The Festival has also played a role in promoting recovery for artists, as well as many of the activists and staff members who have been involved over the years. Being involved in an event that is explicitly about mental health has the potential to enhance positive identities and create opportunities to address self-stigma and openly explore issues relating to mental health that they may only have explored implicitly through their artistic practice. Glasgow-based musician Duglas T. Stewart, who has been involved in the Festival since its first year, described in an interview how the Festival has aided his own recovery:

[The Festival] has allowed me to use some of the most difficult aspects of my adult life for a positive, to find a positive way of making sense [of them] through sharing them with other people. It's just quite empowering ... I think a lot of people who have mental health problems have a feeling of helplessness, and it doesn't make you feel helpless. You just feel [like you've] got a voice and hopefully not just a voice to yourself but hopefully a voice that's for yourself and for other people going through similar sorts of things. (D. T. Stewart, personal communication, November 4, 2016)

\section{The sociopolitical context}

During this phase, the Festival was having a substantial impact across public life. At a policy level, its unique hub-and-spoke model was presented as an example of innovation in international forums ranging from European to the Scottish Government's contribution in transatlantic learning conferences. Nationally, it was being supported by national mental health programs and was recognized by the Scottish Parliament. The Festival was also being recognized by national arts bodies and arts companies, who cited it as a key partner in fulfilling their public purposes, and it had also begun to have an impact on cultural life in Scotland.

This coincided with an overall trend within Scotland towards using the arts to instigate social change. Social issues are embedded into ambitions set out by Creative Scotland, the national development agency for the arts in Scotland, in Unlocking Potential, Embracing Ambition (2014). And, Scotland's progressive political environment has offered a supportive context for a range of social justice festivals to engage with the arts. This has enabled the Festival to explore mental health in the context of wider social issues, including poverty, gender, sexuality, race, and migration. This explicit acknowledgment of the intersectionality of identities, and multiple discriminations, has become one of the most powerful dimensions of the Festival, given that these issues have been shown to have a significant impact on mental health inequities and quality of life for people who experience longterm mental health conditions. However, when expanding the scope of the Festival to encompass these intersecting issues, it has been important that mental health remains the core concern.

\section{Phase three: Mainstreaming mental health}

Although the Festival had instigated the creation of a distinct body of valuable artistic work, and was resonating with broad and diverse audiences, we felt that it had further potential for using the arts to instigate a greater change in main-stream cultural thinking about mental health. The goal of more 
recent phases was to become a fixture in the mainstream Scottish cultural calendar in a way that it never has been before. We have sought to do this by three linked approaches: expanding from an annual event into a year-round arts program, enhancing our reputation for supporting the development of high quality artistic work, and by formally developing an international outlook and partnerships.

This progress has been recognized, and to a great extent made possible, through the receipt of core arts funding from Creative Scotland, the national development agency for the arts, and an investment in two new posts to develop arts and film programming, respectively, during the Festival itself and throughout the year. These posts have been influential in transforming the Festival's approach to programming. The arts lead has extensive experience and a long-standing presence in the arts in Scotland, having previously worked as group arts editor at Scotsman Publications, one of the country's most influential media organizations, while the film lead is a film producer with numerous credits to his name and strong connections within the industry. Equally significantly, both combine this professional experience with lived experience of mental health issues, giving them an enhanced personal connection to what the Festival is trying to do, and greater insight into the challenges associated with bringing stigmatized conditions into the public eye. Speaking about the role, the arts lead said:

I've been living with depression and anxiety for over 20 years, and this is the first professional situation I've been in where I've felt I could talk openly about that without worrying that people would think I wasn't up to the job. If anything, people seem to think it makes me more qualified to do it, and perhaps it does. When I'm talking to artists who are living with mental illness and want to make work about it, it certainly helps create a bond of trust ... I feel empowered but I also feel angry at the negative attitudes we still encounter, and protective towards this festival and all the people involved in it ... . I'm invested in it in a way that feels incredibly personal. (A. Eaton-Lewis, personal communication, November 4, 2016)

In recent years, there has been a focus on developing a program arts events throughout the year. Many of the events that have been established as a result of this are focused on audience development, enabling the Festival to reach people and explore mental health issues outside of the context of the annual event. However, more significantly, the majority of these events are also aimed at developing connections with the artistic and health communities in Scotland and further afield, with a view to creating programming opportunities in the future. An example of the Festival's year-round activities includes A Gala for Mental Health, a showcase event at the Edinburgh Festival Fringe (one of the world's largest arts festivals). We are also curating "mental health" strands within some of the U.K.'s major international film festivals that enable us to reach different audiences and artists.

In addition to simply developing connections, the Festival has made a concerted effort to support the development and exhibition of brand new artistic work. By commissioning new artistic work and proactively seeking relevant work that can be supported from an early stage, the Festival is starting to fulfill an increasingly important role in artistic life in Scotland. Not only is it providing a platform for increasingly high-profile artists with lived experience of mental health to produce related work, but it is also able to provide increased guidance for best practices in representing mental health through the arts, while remaining conscious of protecting artistic freedom. As an example, in 2016, the Festival commissioned a play about Pink Floyd's original frontman Syd Barrett, whose experiences with mental health issues had been well documented but problematically represented in popular culture. Using our experience in the arts and mental health, the Festival team was able to 
play a key role in shaping the script, providing guidance on how to sensitively portray Barrett's experiences with mental health, making it the play's central concern without relying on stigmatizing representations. As a result, the play's mental health themes were explored extensively and positively in the media, while the high-profile nature of the subject matter resulted in U.K.-wide coverage:

No-one can say for sure why Barrett became the "crazy diamond" achingly evoked in a subsequent Pink Floyd anthem. Was he already mentally ill before he became the band's lead guitarist/singer and songwriter? Did the repetitive stress of touring the same material plus the stress of coming up with new hits - push him to distance himself through increasingly wilful behaviour? Or was it ingesting copious amounts of LSD that sent his highly-coloured view of the world into overload? (Brennan, 2016)

The final feature of the Festival's third phase of development is its increasingly international outlook. Approaches to building relationships with artists, arts organizations and other arts festivals have been extended to those operating outside Scotland and the United Kingdom. The Festival is currently involved in a number of projects that transcend national boundaries, including working with a group of similar festivals based in other countries to create a European network of mental health festivals, providing opportunities for exchanging ideas and developing joint programming opportunities. The Festival's International Film Competition has, in the last 2 years, become the primary source for film curation for the main program, giving international filmmakers concerned with mental health issues added incentive to connect with the Festival and become ambassadors for the movement within their own countries. In 2016, more than 1,500 films were submitted from more than 100 countries. Inviting filmmakers to present their work at the Festival has also led to valuable discussions about global mental health identities, contexts, and perspectives, increasing empathy among Scottish audiences, leading to shared understanding and changing ideas about mental health.

\section{Discussion}

\section{Arts and social movements}

Reflecting upon the evolution of the festival over the last decade, we would suggest that the achievements are not unique in the context of social movements more widely but are an important development in the context of mental health. Many social movements use the arts to achieve their goals because it can result in clear outcomes that are necessary, but also because it can challenge deeply embedded and culturally reinforced prejudice. Adams (2002) in her article on arts in social movements highlights not only that this is an under-researched area but also reveals the ways in which arts are used for change ranging from prodemocracy movements, to women's campaigns, through to gospel singing in the civil rights movement. Art plays important roles across social movements such as framing the issues to the wider community, shaping media coverage, proposing solutions, attracting resources, generating emotional engagement, mobilizing support, and mobilizing protest. These are all aspects that we can very directly relate to, though in many cases this has not been planned but has emerged in the course of our development. We would also suggest that the arts have enabled us to make connections across social movements (where mental health can often be marginalized), to be subversive, and to foster opportunities for empowerment for people who have been excluded. It is to this aspect that we will turn our attentions in the next stages of research and development. Although there are many parallels in relation to the use of arts in social movements, we feel that mental health has a particularly powerful and distinct relationship with art. This derives not only from deep-seated beliefs about mental health and creativity, but also 
from the fact that we all have mental health identities that the arts can help surface through emotion.

\section{Tensions}

The biggest challenge that the Festival will continue to face in its third phase of development is the need to balance artistic development with our enduring commitment to the hub-and-spoke model of community coprogramming and coproduction. Given the success of this model, it is vital that the ongoing work does not undermine this. Marginalized groups, including people with lived experience of mental health issues, can feel excluded by mainstream arts organizations and those who are perceived to represent high culture, so it is vital that the Festival continues to involve people at the grassroots level. As the Festival aims to increase its artistic integrity, it is also important that existing audiences are still able to access events by ensuring that they remain affordable and relevant to the communities in which they are produced. And as the Festival continues to reach out internationally, it must ensure that it maintains its Scottish identity, responding to local mental health needs as well as to the wider context.

As the Festival continues to rely on public funding, historically from the health sector and local authorities but increasingly from the arts sector, there will be challenges in terms of contesting the social processes in which funding bodies are embedded. To navigate these structures, the Festival is continually required to redefine the work that it is doing using fixed definitions of what constitutes the arts and mental health campaigns. When the Festival curates complex, even abstract, arts projects, and this is coupled with inherent issues in terms of measuring the impact of arts events in general, it may prove increasingly difficult to allocate its public money set aside for health. Conversely, if it is unable to justify its existence as an arts festival in its own right, it may not be able to continue to attract core arts funding. Given the continued pressure on public funding, these challenges are likely to be on going for the foreseeable future.

\section{Declaration of interest}

The views in this publication are solely the responsibility of the authors. The Commission is not responsible for any use that may be made of the information it contains.

\section{Funding}

This project has received funding from the European Union's Horizon 2020 research and innovation programme under the Marie Skłodowska-Curie grant agreement No 690954.

ORCID

Larry Davidson http://orcid.org/0000-0003-1183-8047

\section{References}

Adams, J. (2002). Art in social movements: Shantytown women's protest in Pinochet's Chile. Sociological Forum, 17(1), 21-56.

Allport, G. W. (1954). The nature of prejudice. Cambridge, MA: Addison-Wesley.

Brennan, M. (2016). Theatre review: One thinks of it all as a dream, Oran Mor, Glasgow. The Herald. Retrieved from http://www.heraldscotland.com/arts ents/14806904.Theatre

review One Thinks of It All as a Dream Oran Mor Glasgow/ 
Corrigan, P. W., \& Watson, A. C. (2002). Understanding the impact of stigma on people with mental illness. World Psychiatry, 1(1), 16-20.

Creative Scotland. (2014). Unlocking potential, embracing ambition. Edinburgh, Scotland: Author.

Health Scotland. (2008). A Review of Scotland's National Programme for Improving Mental Health and Wellbeing 2003-2006. Edinburgh, Scotland: Author.

Inglis, G., Knifton, L., Quinn, N., Dougal, R., \& Byrne, P. (2011). The reach of a national mental health arts and film festival. Glasgow, Scotland: Mental Health Foundation.

Knifton, L., \& Quinn, N. (2008). Media, mental health and discrimination: A frame of reference for understanding reporting trends. International Journal of Mental Health Promotion, 10, 23-31.

Knifton, L., Quinn, N., Inglis, G., \& Byrne, P. (2009). Ethical issues in a national mental health arts and film festival. Journal of Ethics in Mental Health, 4(2), 1-5.

Kuttner, P. J. (2015). What is cultural organising? Online essay. Retrieved from http://culturalorganizing.org/what-is-cultural-organizing/

Miller, P. (2007, October 13). This week. The Herald. Retrieved from https://www.pressreader. com/uk/the-herald-arts/20071013/281530811656259

Myers, F., Woodhouse, A., Whitehead, I., McCollam, A., McBryde, L., Pinfold, V., ... Wilson, L. (2009). Evaluation of 'See Me': The national Scottish campaign against stigma and discrimination associated with mental ill-health. Edinburgh, Scotland: Scottish Executive.

Quinn, N., Shulman, A., Knifton, L., \& Byrne, P. (2011). The impact of a national mental health arts and film festival on stigma and recovery. Acta Psychiatrica Scandinavica, 123, 71-81.

doi:10.1111/j.1600-0447.2010.01573.x

Scottish Arts Council. (2008). Travel and tourism: Taking part in Scotland 2008. Edinburgh, Scotland: Author.

Scottish Government. (2009). Towards a mentally flourishing Scotland: Policy and action plan 20092011. Edinburgh, Scotland: Author.

World Federation for Mental Health. (2010). World mental health day. Mental Health in Family Medicine, 7(2), 123. 310alorganizing.org/what-is-cultural-organizing/ 